\title{
HUBUNGAN TINGKAT PENGETAHUAN KOGNITIF DENGAN KEMAUAN MELAKUKAN CARDIOPULMONARY RESUSCITATION (CPR) PADA REMAJA DI SMAN MALANG
}

\author{
Rahmawati Maulidia ${ }^{1}$, Nining Loura ${ }^{2}$ \\ IImu Keperawatan STIKes Maharani Malang \\ E-mail : rahmawatimaulidia61@gmail.com
}

\begin{abstract}
The action that connects survivors of cardiac arrest is called the Chain of Survival. Chain of Survival. The role of CPR bystander is very important to save cardiac arrest victims, therefore training and knowledge about CPR are being disseminated to ordinary people including in Indonesia. According to a preliminary study obtained by researchers, education about basic life assistance has been taught in several state high schools in Malang, especially in material taught at the Youth Red Cross (PMR). The purpose of this study is to to determine the relationship of cognitive knowledge level with the willingness to perform cardiopulmonary resuscitation (CPR) in adolescents in poor public high schools. Method In this research, This study used a correlational analytic design with a crossectional approach to determine the relationship of cognitive knowledge level with the willingness to perform cardiopulmonary resuscitation (CPR) in adolescents. The study sample consisted of 76 respondents. The sampling technique uses cluster sampling. The inclusion criteria for nurses were as follows: PMR members in Malang State High School who were still active, students who were willing to become respondents. While the exclusion criteria: students who are not present at the time of data collection and experience disability / disability. The independent variable of this study is the level of cognitive knowledge while the dependent variable is the willingness to do. The instrument in this study used a questionnaire CPR. Statistical results using the Chi Square test show that the $p$ value is $0.002(<0.05)$. This shows that there is a relationship between the level of cognitive knowledge and the willingness to do CPR in adolescents in Malang Senior High School. The better the cognitive cognitive level of a person, the higher a person's willingness to do CPR. Willingness to do CPR will help in minimizing the incidence of cardiac arrest in the community.
\end{abstract}

\section{Keywords : Cardiopulmonary Resuscitation (CPR), Willingness, Level of Cognitive Knowledge}

Abstrak : Tindakan yang menghubungkan korban henti jantung dengan kelangsungan hidup disebut Chain of Survival. Chain of Survival. Peran bystander CPR sangat penting untuk menyelamatkan korban henti jantung, oleh karena itu pelatihan dan pengetahuan tentang CPR mulai disebarluaskan untuk masyarakat awam termasuk di Indonesia. Menurut studi pendahuluan yang didapatkan peneliti, edukasi tentang bantuan hidup dasar sudah pernah diajarkan di beberapa SMA Negeri di Malang terutama dalam materi yang diajarkan di Palang Merah Remaja (PMR). Penelitian ini bertujuan untuk mengetahui hubungan tingkat pengetahuan kognitif dengan kemauan melakukan cardiopulmonary resuscitation (CPR) pada anak remaja di SMA negeri malang. Metode Penelitian ini menggunakan desain analitik korelasional dengan pendekatan crossectional untuk mengetahui hubungan tingkat pengetahuan kognitif dengan kemauan melakukan cardiopulmonary resuscitation (CPR). Sampel penelitian terdiri 76 responden. Teknik sampling mengunakan cluster sampling. Kriteria inklusi perawat sebagai berikut: anggota PMR di SMA Negeri Malang yang masih aktif, siswa yang bersedia menjadi responden. Sedangkan kriteria eksklusi: siswa yang tidak hadir pada saat pengambilan data dan mengalami disabilitas/difabel. Variabel independent penelitian ini adalah tingkat pengetahuan kognitif sedangkan variable dependentnya kemauan melakukan CPR. Instrumen yang digunakan yaitu lembar kuesioner. Hasil statistik dengan menggunakan uji Chi Square menunjukkan bahwa nilai $\mathrm{p}$ adalah $0,002(<0,05)$. Hal ini menunjukkan bahwa ada hubungan antara tingkat pengetahuan kognitif dengan kemauan melakukan CPR pada remaja di SMAN Malang. Semakin baik tingakt pengetahuan kognitif seseorang maka semakin tinggi kemauan seseorang untuk melakukan CPR. Kemauan melakukan CPR akan membantu dalam meminimalisir kejadian henti jantung di masyarakat.

Kata Kunci : Cardiopulmonary Resuscitation (CPR), Kemauan, Tingkat Pengetahuan Kognitif

\section{PENDAHULUAN}

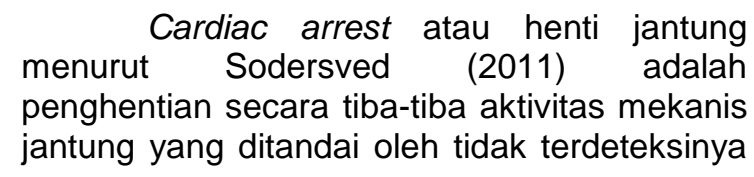

nadi (pulse), unresponsiveness dan apnea (agonal, pernafasan gasping). Tanda - tanda terpenting dari kasus henti jantung bisa dilihat pada monitor jantung seperti ventricular fibrillation, ventricular tachycardia atau pulseless electrical activity, dan apabila tidak 
dilakukan CPR maka kondisi tersebut akan menyebabkan kematian (Vaillancourt at al., 2008).

Data dari American Heart Association yang dilaporkan oleh Heart Disease and Stroke Statistics tahun 2013 menyebutkan bahwa terdapat perbedaan angka kejadian insiden Cardiac Arrest di dalam dan di luar rumah sakit. Insiden henti jantung di luar rumah sakit atau Out-of Hospital Cardiac Arrest (OHCA) yaitu sebanyak 382.800 di tahun 2012 dan sebanyak 359.400 di tahun 2013. Insiden Insiden Cardiac Arrest di dalam rumah sakit atau In Hospital Cardiac Arrest (IHCA) sebanyak 209.000 di tahun 2012, dan dengan jumlah yang sama di tahun 2013 (Alan et al., 2013). Sesuai dengan pemaparan di atas, maka terbukti bahwa kejadian henti jantung di luar rumah sakit lebih banyak dibandingkan di dalam rumah sakit. Sedangkan jumlah prevalensi penderita henti jantung di Indonesia tiap tahunnya belum diadapatkan data yang jelas, namun diperkirakan sekitar 10 ribu warga, yang berarti 30 orang per hari (Depkes, 2006).

Tindakan yang menghubungkan korban henti jantung dengan kelangsungan hidup disebut Chain of Survival. Chain of Survival terdiri dari segera mengenali tanda henti jantung dan mengaktifkan bantuan gawat darurat, segera melakukan basic life support dengan penekanan pada kompresi dada, segera melakukan defibrilasi jika ada indikasi, bantuan hidup lanjut yang efektif, dan perawatan post henti jantung yang integratif (Travers et al., 2010). Menurut Hirose et al. (2014) tiga rantai pertama sangat penting untuk kelangsungan hidup korban OHCA. Bystander (seseorang yang pertamakali melihat kejadian henti jantung) yang mengaplikasikan rantai pertama akan memberikan kesempatan bagi operator untuk membantu bystander tersebut untuk membantu mengidentifikasi kondisi pasien, mengurangi rasa takut bystander, dan mengarahkan untuk memulai melakukan CPR, sehingga pada saat mengaplikasikan rantai kedua dapat menambah efektifitas dalam kelangsungan hidup korban, yaitu menjadi dua kali lipat (Lerner et al., 2012). Rantai ketiga adalah segera melakukan defibrilasi jika ada indikasi, dimana menurut Capucci et al. (2002) di Rochester, Minnesota, pertolongan henti jantung yang dilengkapi dengan AED (Automatic External Defibrillation) mempunyai tingkat kelangsungan hidup $45 \%$ untuk untuk korban Ventricular fibrilation (VF) yang merupakan penyebab paling banyak untuk kasus henti jantung.

Di Indonesia, henti jantung dialami oleh Raden Pandji Chandra Pratomo Samiadji Massaid yang merupakan anggota DPR-RI periode 2004-2009 dan 2009-2014, Ida Kusumah, dan Ricky Johannes, namun nyawa mereka tidak bisa diselamatkan karena langsung dilarikan ke rumah sakit, tanpa ada pertolongan awal yakni CPR. Pernyataan di atas telah membuktikan bagaimana pentingnya peran bystander CPR dalam berkontribusi meningkatkan kelangsungan hidup korban OHCA.

Peran bystander CPR sangat penting untuk menyelamatkan korban henti jantung, oleh karena itu pelatihan dan pengetahuan tentang CPR mulai disebarluaskan untuk masyarakat awam termasuk di Indonesia. Menurut studi pendahuluan yang didapatkan peneliti, edukasi tentang bantuan hidup dasar sudah pernah diajarkan di beberapa SMA Negeri di Malang terutama dalam materi yang diajarkan di Palang Merah Remaja (PMR). Menurut Cave at al. (2011), meningkatnya presentase mahasiswa dan staff perguruan tinggi akan meningkatkan kemungkinan seseorang segera memulai CPR untuk korban henti jantung di luar rumah sakit. Alasan banyak dilakukan edukasi untuk mahasiswa karena telah bisa memberikan teknik kompresi dada yang benar, berhubungan dengan usia, tinggi, dan berat badan mereka (Jones, 2007), selain itu siswa yang dilatih CPR sejak dini dapat dijadikan sebagai strategi jangka panjang untuk menyebarkan pengetahuan yang mereka dapat kepada masyarakat luas (Lesnik at al., 2011)

Penelitian yang dilakukan Kuramoto et al. (2008) di Jepang mendapatkan data bahwa hanya $13 \%$ masyarakat yang bersedia melakukan CPR kepada keluarga dan temantemannya, dan hanya $7 \%$ yang bersedia melakukan CPR kepada orang asing. Faktor psikososial seperti serangan panik, kehawatiran tidak dapat melakukan CPR dengan benar, takut merugikan korban dan keyakinan bahwa orang tersebut sudah meninggal juga menjadi faktor penentu kemauan bystander untuk melakukan CPR (Coons and Guy, 2009). Dari hasil penelitian tersebut dapat disimpulkan bahwa korban OHCA masih banyak yang tidak tertolong nyawanya meskipun sudah dilakukan penyebaran edukasi dan pelatihan tentang melakukan CPR kepada masyarakat. Kondisi yang sangat kompleks di atas mendorong penulis untuk melakukan penelitian tentang tingkat pengetahuan kognitif dengan kemauan remaja melakukan Cardiopulmonary Resuscitation (CPR). Tujuan dilakukannya penelitian ini yaitu untuk mengetahui hubungan tingkat pengetahuan kognitif dengan kemauan melakukan cardiopulmonary resuscitation (CPR) pada anak remaja di SMA negeri malang. 


\section{BAHAN DAN METODE}

Penelitian ini menggunakan desain analitik korelasional dengan pendekatan crossectional. Sampel penelitian terdiri 76 responden yang terdiri dari anggota PMR dari SMP di SMA Negeri 7, SMAN 8 dan SMAN 9.Teknik sampling Cluster sampling pada responden yang memenuhi kriteria inklusi. Kriteria inklusi perawat sebagai berikut: anggota PMR di SMA Negeri Malang yang masih aktif, siswa yang bersedia menjadi responden. Sedangkan kriteria eksklusi: siswa yang tidak hadir pada saat pengambilan data dan mengalami disabilitas/difabel.

Intervensi dilakukan mulai tanggal 10 ,17 da 19 Mei 2017 diawali dengan mengajukan izin penelitian dan pengambilan data ke SMPN Kota Malang dilanjutkan dengan memberikan penjelasan tentang maksud dan tujuan penelitian pada responden dan memberi kesempatan kepada responden yang bersedia mengikuti penelitian untuk menandatangani lembar persetujuan menjadi responden. Melakukan kontrak tempat dan waktu kepada responden. Memberikan kuesioner kepada responden dan mengumpulkan kembali kuesioner yang telah diisi responden. Melakukan pengolahan data dan analisis data dengan menggunakan uji Chi Square dan terakhir pengambilan kesimpulan serta membuat laporan penelitian.

\section{HASIL}

Hasil analisis dari data demografi didapatkan data umum responden berdasarkan usia paling banyak usia 15-16 tahun yaitu sebesar $59,2 \%$. Sedangkan data responden berdasarkan jenis kelamin paling banyak perempuan $76,3 \%$. Data khusus hasil penelitian didapatkan beberapa grafik diantaranya:

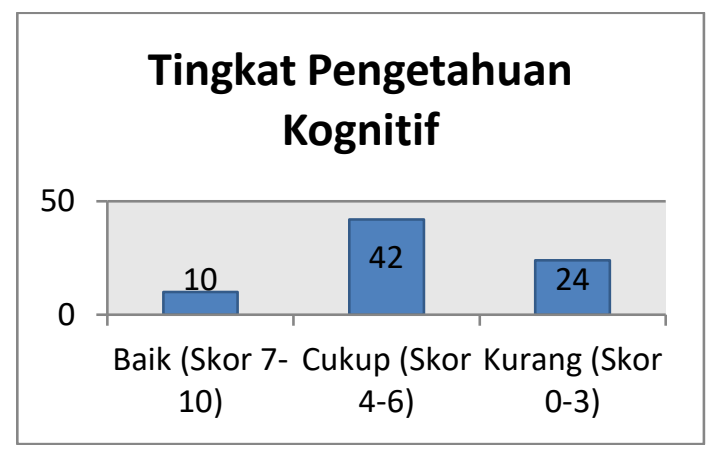

\section{Gambar 1. Grafik Karakteristik Responden Berdasarkan Tingkat Pengetahuan Kognitif}

Berdasarkan grafik diatas dapat disimpulkan bahwa dari 76 responden paling banyak 42 siswa (55\%) memiliki tingkat pengetahuan kognitif cukup (skor 4-6).

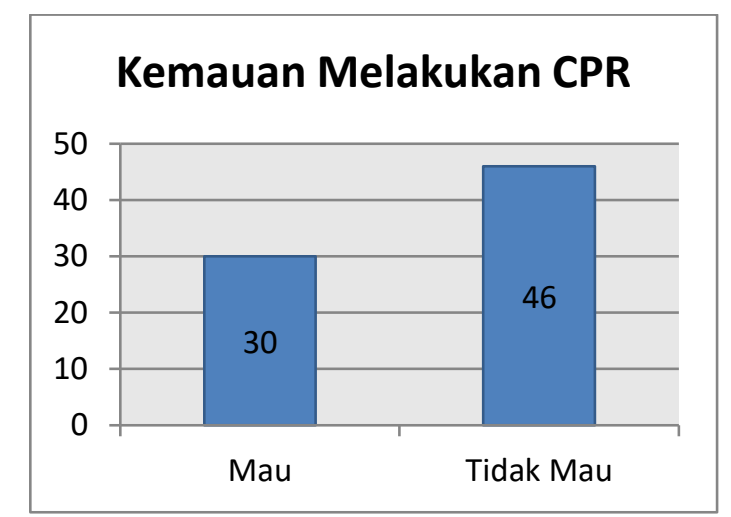

\section{Gambar 2. Grafik Karakteristik responden berdasarkan Kemauan Melakukan CPR}

Berdasarkan grafik diatas dapat disimpulkan bahwa dari 76 responden yang diteliti didapatkan sebanyak 30 siswa (39\%) mau melakukan CPR dan 46 siswa (61\%) tidak mau melakukan CPR dengan alasan masih belum berpengalaman (56\%), tidak percaya diri
(33\%) dan tidak berani mengambil resiko jika terjadi sesuatu (11\%)

Hasil analisis data menggunakan uji Chi-Square Berdasarkan tabel di atas, pada selang kepercayaan 95\% menunjukkan hasil bahwa nilai $p<0,05$ yaitu 0,002 , dimana 
terdapat hubungan tingkat pengetahuan kognitif dengan kemauan melakukan CPR pada anak remaja SMA Negeri Malang.

\section{PEMBAHASAN}

\section{Tingkat Pengetahuan Kognitif Siswa Remaja tentang CPR}

Berdasarkan hasil penelitian dengan

76 responden menunjukkan bahwa sebagian besar siswa memiliki tingkat pengetahuan kognitif yang cukup 42 responden dan kurang 24 responden karena sebelumnya meskipun responden telah mendapatkan materi dan pelatihan dari masing-masing institusi pendidikan tentang CPR namun kurang mendalam dan belum pernah mendapatkan paparan tentang kejadian jantung yang dapat terjadi setiap waktu dan bagaimana cara penatalaksanaanya. Hal ini sesuai dengan teori bahwa pelatihan pada prinsipnya ada kegiatan proses pembelajaran baik teori maupun praktek yang bertujuan meningkatkan dan mengembangkan kompetensi atau kemampuan akademik, sosial dan pribadi di bidang pengetahuan, keterampilan dan sikap (Notoatmodjo, 2005). Hasil penellitian Chew et al. (2009) juga mengatakan bahwa setelah dilakukan pelatihan CPR pada mahasiswa dan dosen, kemauan untuk melakukan CPR akan meningkat. Selain itu penelitian yang dilakukan oleh Lesnik et al. (2011) menyatakan bahwa terdapat peningkatan pengetahuan setelah dilakukannya pelatihan tentang CPR pada mahasiswa. Villancourt et al. (2008) mengatakan bahwa berbagai sumber telah menyebutkan terdapat hubungan yang signifikan terhadap peningkatan pengetahuan setelah dilakukannya pelatihan CPR.

Pengalaman merupakan suatu cara untuk memperoleh kebenaran dari pengetahuan. Hal ini dilakukan dengan cara mengulang kembali pengetahuan yang diperoleh dalam memecahkan permasalahan yang dihadapi pada masa lalunya. Sedangkan melalui penyuluhan, pengetahuan masyarakat tentang suatu objek dapat meningkat (Budiman, 2013). Pengukuran pengetahuan ini dilakukan dengan menanyakan tentang indikasi dilakukan CPR, konsep C-A-B, mengkaji lokasi kejadian, mengkaji respon korban, nadi dan pernafasan, pengaktifan bantuan EMS, teknik kompresi dada, kedalaman kompresi dada, kecepatan kompresi dada, menghentikan kompresi dada saat bantuan datang, dan konsep defibrilasi. Dapat disimpulkan bahwa tingkat pengetahuan kognitif siswa SMA Negeri 7,8 dan 9 Malang masih cukup dan kurang, terbukti dengan hasil penelitian yang menyebutkan dari 76 siswa yang menjadi responden, 42 di antaranya memiliki tingkat pengetahuan kognitif cukup dan 24 memiliki tingkat pengetahuan kognitif kurang . Sehingga diharapkan siswa meningkatkan pengetahuan tentang CPR melalui ekstrakulikuler PMR sehingga bisa meningkatkan kemauan untuk melakukan CPR.

\section{Kemauan Melakukan CPR}

Berdasarkan dari kemauan melakukan CPR didapatkan bahwa dari 76 responden yang diteliti didapatkan sebanyak 30 siswa mau melakukan CPR dan 46 siswa tidak mau melakukan CPR dengan alasan masih belum berpengalaman, tidak percaya diri dan tidak berani mengambil resiko jika terjadi sesuatu. Kemauan sendiri, pada dasarnya merupakan faktor penggerak yang berasal dari dalam diri seseorang yang diarahkan oleh pikiran dan perasaan mereka sendiri (Murdoko, 2003). Sehingga kata hati dan lingkungan merupakan pemegang peranan penting dalam menimbulkan kemauan tersebut (Ahmadi, 2003). Kemauan menolong ini dipengaruhi oleh beberapa faktor, yaitu usia penolong, tingkat pendidikan, pengetahuan tentang pentingnya RJP, pengetahuan dan kemampuan dalam melakukan RJP dan ketersediaan AED (Automatic External Defibrilatio). Selain itu adanya faktor psikososial yang juga mempengaruhi seperti serangan panik, kehawatiran tidak dapat melakukan CPR dengan benar, takut merugikan korban dan keyakinan bahwa orang tersebut sudah meninggal juga menjadi faktor penentu kemauan bystander untuk melakukan CPR (Coons and Guy, 2009).

$$
\text { Pada distribusi responden }
$$

berdasarkan faktor intrapersonal didapatkan hampir sebagian besar dipengaruhi oleh faktor dari dalam individu tersebut saat memutuskan untuk melakukan tindakan CPR pada korban. Faktor intrapersonal yang akan medorong seseorang untuk mewujudkan ataupun tidak dalam bentuk aksi nyata. Sesuai dengan pendapat Baron (2005) yang mengatakan bahwa perilaku menolong semata-mata dipengaruhi oleh faktor intrapersonal (faktor yang ada di dalam orang tersebut) meliputi suasana hati (mood), empati, motivasi dan kepribadian responden juga tidak terlepas dari pertimbangan-pertimbangan internal untuk memilih menjadi egois atau prososial.

Sedangkan pada distribusi faktor psikososial didapatkan bahwa sebagian besar responden tidak merasa dipengaruhi oleh faktor psikososial. saat memutuskan untuk melakukan tindakan CPR pada korban. Menurut Baron, 2005, unsur-unsur yang termasuk faktor psikososial yang mempengaruhi seseorang mau atau tidaknya memberi pertolongan adalah norma yang berlaku, perasaan kesamaan kelompok, daya tarik yang dimiliki korban, kedekatan 
hubungan, nilai ekonomi serta situasi social yang berlaku saat kejadian. Namun unsurunsur tersebut kurang kuat untuk mendorong seseorang melakukan tindakan pertolongan. Menurut peneliti yang menjadi alasan faktor psikosoial kurang berpengaruh antara lain adanya kemungkinan adanya penurunan dari masyarakat terhadap norma yang berlaku, sebagian korban henti jantung bukan anggota keluarga terdekat atau mungkin tidak berani menerima tanggung jawab dalam menolong.

Selain kedua faktor diatas, ada pula faktor situasional, dimana didapatkan seluruh responden dipengaruhi oleh faktor tersebut. Menurut Baron 2005, faktor situasional yang dimaksud dalam penelitian ini adalah penolong menyadari situasinya, mampu mengintepretasikan situasi, asumsi bahwa sudah menjadi tanggung jawabnya untuk menolong, mengetahui apa yang harus dilakukan dan mengambil keputusan untuk menolong. Intepretasi yang tepat bahwa situasi yang gawat darurat akan mendorong kemauan seseorang untuk memberikan bantuan. Namun kondisi kegawatdaruratan sering kali memerlukan skiil khusus yang biasanya orang awam tidak mampu melakukannya, seperti korban henti jantung dimana seorang penolong harus memiliki skill dan pengalaman khusus untuk memberikan pertolongan, tidaklah cukup adanya keinginan yang kuat tanpa adanya skill yang memadai. Sehingga sangatlah penting bagi remaja PMR menjadi tenaga terlatih demi meningkatkan pelayanan prehospital, karena penanganan prehospital menjadi penentu angka harapan hidup korban henti jantung.

Hubungan Tingkat Pengetahuan Kognitif dengan Kemauan Melakukan CPR pada di Malang

Tingkat pengetahuan kognitif sangat erat kaitannya dengan kemauan untuk melakukan Cardiopulmonary Resuscitation (CPR). Pernyataan ini didukung oleh hasil penelitian yang dilakukan oleh Taniguchi T, Omi W, Inaba H. (2007) yang melakukan penelitian tentang sikap terhadap kinerja bystander di Jepang. Hasil yang dikemukakan ialah sekitar $70 \%$ dari subyek sudah pernah melakukan pelatihan CPR, ada sekitar 10-30\% dari siswa sekolah menengah atas, guru dan penyedia layanan kesehatan yang melaporkan kemauannya untuk melakukan CPR dan Mouth-to-Mouth Ventilation (MMV) dan sekitar $70-100 \%$ dari subyek yang mau melakukan hands-only CPR. Oleh karena itu, tingkat pengetahuan yang tinggi diharapkan dapat menjadikan seseorang untuk melakukan CPR.

Berdasarkan uji Kontingensi untuk kemauan melakukan CPR menunjukkan terdapat hubungan tingkat pengetahuan kognitif dengan kemauan melakukan CPR pada anak remaja SMA Negeri Malang dengan nilai $p=0,002$ dimana $p<0,05$ sehingga Ho ditolak. Kemauan sendiri, pada dasarnya merupakan faktor penggerak yang berasal dari dalam diri seseorang yang diarahkan oleh pikiran dan perasaan mereka sendiri (Murdoko, 2003). Sehingga kata hati dan lingkungan merupakan pemegang peranan penting dalam menimbulkan kemauan tersebut (Ahmadi, 2003). Pemaparan ini dapat dilihat dari alasan responden tidak mau melakukan karena mereka merasa tidak mampu dan tidak mempunyai skill serta pengetahuan yang cukup dalam melakukan CPR. Hal ini sesuai dengan hasil penelitian dari Guy et al. (2010) bahwa pemberian materi dan pelatihan CPR akan meningkatkan kepercayaan diri dan kemauan untuk melakukan CPR.

Celenza et al. (2002) mengatakan bahwa rendahnya pengetahuan akan mempengaruhi kepercayaan diri masyarakat untuk melakukan CPR. Sedangkan menurut Jelinek et al. (2001), kemauan melakukan CPR pada masyarakat dipengaruhi oleh keefektifan pelatihan pada bystander. Kuramoto et al. (2008) dalam jurnalnya menyebutkan bahwa pengalaman, pelatihan CPR serta pengalaman melakukan CPR secara actual mempunyai dampak terhadap kemauan bystander. Hal ini bertolak belakang dengan yang dikemukan oleh Chew et al. (2009) bahwa tingkat pengetahuan kognitif yang tinggi bukan berarti seseorang akan mempunyai kemauan untuk melakukan CPR. Pernyataan ini didukung oleh hasil penelitian yang dilakukan oleh Urban (2013), kemauan melakukan CPR tidak hanya dipengaruhi oleh tingkat pengetahuan, namun ada faktor lain sseperti jenis CPR yang dilakukan, mouth-to-mouth atau hands only CPR.

Sehingga menurut peneliti dapat disimpulkan bahwa kemauan untuk melakukan tindakan CPR ini ditentukan oleh banyak faktor, terutama dalam hal pengetahuan CPR, pengalaman pelatihan CPR dan pengalaman melakukan CPR pada korban henti jantung. Pengetahuan kognitif saja tidak cukup untuk menumbuhkan adanya kemauan melakukan tindakan CPR, dimana CPR merupakan suatu tindakan pertolongan pertama terhadap korban henti jantung yang termasuk ketegori kasus kegawatdaruratan dimana tanggunggugat (tanggung jawab dan tanggung gugat) seorang penolong dipertaruhkan.

\section{KESIMPULAN}

Tingkat pengetahuan kognitif tentang CPR pada Anak Remaja di SMA Negeri Malang sebagian besar cukup dan sebagian besar Anak Remaja di SMA Negeri Malang tidak mau melakukan CPR dengan alasan masih belum berpengalaman, tidak percaya 
diri dan tidak berani mengambil resiko jika terjadi sesuatu. Terdapat hubungan tingkat pengetahuan kognitif dengan kemauan melakukan CPR pada Anak Remaja di SMA Negeri Malang

\section{SARAN}

\section{Bagi Ilmu Pengetahuan}

Pelatihan Cardiopulmonary

Resuscitation terhadap siswa dapat dikembangkan untuk membantu meningkatkan pengetahuan dan bagaimana tata laksana CPR untuk korban henti jantung yang belum diketahui riwayat penyakitnya. Koordinasi dan kerjasama antara institusi dengan pihak Palang Merah Indonesia cabang Malang atau instansi terkait lainnya untuk tetap rutin

\section{DAFTAR PUSTAKA}

Adam (2013) dalam Utami ISP, Soemardini, Fathony M. (2014). Pengaruh Pelatihan Resusitasi Jantung Paru Terhadap Peningkatan Pengetahuan Bantuan Hidup Dasar Pada Siswa Sma Brawijaya Smart School Malang.

Ahmadi, A. (2009). Psikologi Umum. Jakarta : Rineka Cipta.

Alan S, Dariush M, Roger VL, Benjamin EJ, Jarett DB, William BB, Dawn MB, et al. (2013). Heart Disease and Stroke Statistics-2013 Update: A Report From the American Heart Association. Circulation. 2013;127:000-000.

Alkatiri J. (2007). Resusitasi Kardio Pulmoner dalam Sudoyo W. Buku Ajar IImu Penyakit Dalam. Jilid I. Edisi IV. Jakarta : FKUI.

Arikunto, S. (2006). Prosedur Penelitian. Jakarta: Rineka Cipta.

Asih, G. Y., \& Pratiwi, M. M. (2010). Perilaku Prososial Ditinjau Dari Empati dan Kematangan Emosi. Jurnal Psikologi Universitas Muria Kudus, 1(1), 33-42.

Baron, R.A.,\& Byrne,D., (2005). Psikologi Sosial, Jilid II, Edisi 10. Jakarta: Erlangga

Berg MD, Schexnayder SM, Chameides L, Terry M, Donoghue A, Hickey RW, Sutton, Hazinski MF. (2010). Part 13: pediatric basic life support: 2010 American Heart Association Guidelines for Cardiopulmonary Resuscitation and Emergency Cardiovascular Care. Circulation. 2010;122(suppl 3):S862S875. memberikan edukasi dan pelatihan kepada siswa tentang CPR.

\section{Bagi peneliti selanjutnya,}

penelitian sebaiknya dilakukan pada seluruh siswa SMA di Malang, baik dari Sekolah Negeri maupun Sekolah Swasta dengan lebih mempertimbangkan kriteria inklusi dan eksklusi dan diharapkan teknik pengambilan data lebih akurat, misalnya pengisian kuisioner dengan pendampingan dari peneliti sendiri.

\section{Bagi penelitian selanjutnya,}

Disarankan untuk memberikan edukasi dan pelatihan langsung kepada siswa SMA sehingga pengetahuan kognitif dapat dikonfirmasi juga dengan pengetahuan psikomotornya.

Bintaranny, K. (2012, January 14). Teori Tentang Psikososial. Retrieved May 21, 2014, from http://informasitips.com/teoritentang-psikososial

Budiman. (2013). Kapita Selekta Kuesioner: Pengetahuan dan Sikap dalam Penelitian Kesehatan. Jakarta: Salemba Medika.

Capucci A, Aschieri D, Massimo FP, Gust HB, Efrosini I, and Maurizio A. (2002). Tripling Survival From Sudden Cardiac Arrest Via Early Defibrillation Without Traditional Education in Cardiopulmonary Resuscitation. Circulation. 2002;106:1065-1070

Cave DM, Aufderheide TP, Beeson J, Ellison A, Gregory A, Hazinsky MF, et al. (2011). Importance and implementation of training in cardiopulmonary resuscitation and automated external defibrillation in schools: a science advisory from the american heart association. Circulation 2011, 123(6):691-706.

Celenza T, Gennat HC, O'brien D, Jacobs IG, Lynch DM, Jelinek GA. Community competence in cardiopulmonary resuscitation. Resuscitation 2002;55:157-65.

Chew KS, Yazid MNA, Kamarul BA, Rashidi A. (2009). Translating Knowledge to Attitude : A Survey on the Perception oy Bystander Cardiopulmonary Resuscitation Among Dental Students in Universiti Sains Malaysia and School Teachers in Kota Bharu, Kelantan. Med J Malaysia Vol 64 No 3 September 2009. 
Coons SJ, Guy MC. (2009). Performing bystander CPR for sudden cardiac arrest: Behavioral intentions among the general adult population in Arizona. Resuscitation 2009, 334-340.

Departemen Kesehatan. (2006). Pharmaceutical care untuk pasien penyakit jantung koroner: Fokus sindrom koroner akut

Gyu CC, You DS, Ku HK, Won WL, Kyung SL, Won K, et al. (2010). The Effect of Basic Life Support Education on Laypersons' Willingness in Performing Bystander Hands Only Cardiopulmonary Resuscitation. Resuscitation 2010, 691694.

Hall, C. S and Lindzey, G. (1993). Teori Psikodinamik (klinis). Jakarta: Kanisius.

Hidayat. 2007. Metode Penelitian Keperawatan dan Tekhnik Analisa Data. Jakarta: Salemba Medika

Hirose $T$, Iwami $T$, Ogura $H$, Matsumoto $H$, Sakai T, Yamamoto K, et al. (2014). Effectiveness of a simplified cardiopulmonary resuscitation training program for the non-medical staff of a university hospital. Scandinavian Journal of Trauma, Resuscitation and Emergency Medicine 2014, 22:31

Jelinek GA, Gennat H, Celenza T, O'Brien D, Jacobs I, Lynch D. Community attitudes towards performing cardiopulmonary resuscitation in Western Australia. Resuscitation 2001;51:239-46.

Jones, I. (2007). At What Age Can Schoolchildren Provide Effective Chest Compressions ? An Observasional Study from The Heartstart UK School Training Programme. A Science Advisory From The American Heart Association. Circulation 2007;123:9871-706

Karunia, D. T. (2012). Keterkaitan Kepribadian dan Elemen Perilaku terhadap Peningkatan Kinerja Karyawan (670158). Retrieved from Academia edu

Kuramoto N, Morimoto T, Kubota Y, Maeda Y, Seki S, Takada K, Hiraide A. (2008). Public perception of and willingness to perform bystander CPR in Japan. Resuscitation (2008) 79, 475-481.

Lancet. (2010). Resusitasi Anak. Health Education Research, 375: 1347-54.

Lerner EB, Rea TD, Bobrow BJ, Acker JE, Berg AB, Brooks SC, et al. (2012). Emergency Medical Service Dispatch Cardiopulmonary Resuscitation Prearrival Instructions to Improve Survival From Out-of-Hospital Cardiac Arrest : A Scientific Statement From the American Heart Association. Circulation. 2012;125:648-655.
Lesnik D, Lesnik B, Golub J, Krizmaric M, Mally S, Grmec S. (2011). Impact of Additional Module Training on The Level of Basic Life Support Knowledge of First Year Students at The University of Maribor. International Journal of Emergency Medicine 2011, 4:16

Meisnner TC and Christoph Hanefeld. (2012). Basic Life Support Skill of High School Students Before and After Cardiopulmonary Resucitation Training: a Longitudinal Investigation. Scandinavian Journal of Trauma, Resuscitation and Emergency Medicine, 20.

Mubarak, WI. (2007). Promosi Kesehatan: Sebuah pengantar Proses Belajar Mengajar dalam Pendidikan. Yogyakarta: Graha IImu

Murdoko, E. W. H. (2006). Personal Quaity Management. Jakarta : Elex Media Komputindo

Nolan JP, Soar J, Zideman DA, Biarent D, Bossaert LL, Deakin C, et al. (2010). European Resuscitation Council : Summary of the main changes in the Resuscitation Guidelines 2010. In Press

Notoadmojo, S. (2005). Pendidikan dan Perilaku Kesehatan. Jakarta: Rineka Cipta.

Notoadmojo, S. (2007). Pendidikan dan Perilaku Kesehatan. Jakarta: Rineka Cipta.

Nursalam. (2008). Konsep dan Penerapan Metodologi Penelitian IImu Keperawatan : Pedoman Skripsi, Tesis, dan Instrumen Penelitian Keperawatan. Jakarta: Salemba Medika

Palang Merah Indonesia. (2013). Korps Sukarela (KSR) PMI.

Pratomo, H. (1986). Pedoman Pembuatan Usulan Penelitian Bidang Kesehatan Masyarakat dan Keluarga Berencana/Kependudukan. Jakarta: Departemen Pendidikan dan Kebudayaan RI PMU Pengembangan FKM di Indonesia

Saryono. (2011). Metodologi Penelitian Kesehatan. Jogjakarta: Mitra Cendekia. Sayre MR, Berg RA, Cave DM, Page RL, Potts J,White RD. (2008). Hands-only (compression-only) cardiopulmonary resuscitation : a call to action for bystander response to adults who experience out-of-hospital sudden cardiac arrest. Circulation. 117:2162-2167.

Setiawan. (2011). Hubungan Gambaran Diri dengan Tingkat Depresi Penderita Ulkus Diabetes Melitus di RSUD Kraton Kabupaten Pekalongan. Tesis. Tidak diterbitkan. Universitas Muhammadiyah Semarang. 
Sharma R, Attar NR. (2012). Adult Basic Life Support (BLS) Awareness and Knowledge Among Medical and Dental Interns Completing Internship From Deemed University. Nitte University Journal of Health Sciene Vol. 2, September 2012, ISSN 2249-7110.

Sodersved K. (2011). In-Hospital Cardiac Arrest. A study of Education in Cardiopulmonary Resuscitation and Its Effects on Knoeledge, Skill and Attitudes among Health Care Professsionals and Survival on In-Hospital Cardiac Arrest Patients. Acta Universitatis Upsaliensis. Digital Comprehensive Summaries of Uppsala Disertations from the faculty of Medicine 664. 90 pp. Uppsala. ISBN 97891-554-8050-9.

Soemanto, Wasty. (1987). Psikologi Pendidikan. Jakarta: Bina Aksara.

Sugiyono. (2009). Metode Penelitian Kuantitatif, Kualitatif dan R\&D. Bandung : Alfabeta

Taniguchi T, Omi W, Inaba H. Attitudes toward the performance of bystander cardiopulmonary resuscitation in Japan. Resuscitation.2007;75(1):82-87

Travers AH, Rea TD, Bobrow BJ, Edelson DP, Berg RA, Sayre MR, et al. (2010). Part 4: CPR Overview: 2010 American Heart Association Guidelines fof Cardiopulmonary Resuscitation and Emergency Cardiovascular Care. Circulation 2010;122;S676-S684
Urban J, Thode $\mathrm{H}$, Stapleton E, Singer AJ. (2013). Current Knowledge of and Willingness to Perform Hands-Only CPR in Layperson. Resuscitation 84 (2013) 1574-1578.

Utami ISP, Soemardini, Fathony M. (2014). Pengaruh Pelatihan Resusitasi Jantung Paru Terhadap Peningkatan Pengetahuan Bantuan Hidup Dasar Pada Siswa Sma Brawijaya Smart School Malang.

Vaillancourt C, Grimshaw J, Brehaut JC, Osmond M, Charette ML, Wells GA, Still IG. (2008). A Survey Of Attitudes And Factors Associated With Successful Cardiopulmonary Resuscitation (CPR) Knowledge Transfer In An Older Population Most Likely To Witness Cardiac Arrest: Design And Methodology. BMC Emergency Medicine 2008, 8:13 